\title{
THE PLACE OF ALLERGY IN ASTHMA
}

\author{
By A. W. Frankland, M.A., D.M. \\ The Medical Officer in charge, Allergy Department, The Wright-Fleming Institute, St. Mary's Hospital, London
}

One of our difficulties in deciding the importance of allergy in asthma stems from difficulties in defining terms. An allergic reaction can be defined as a specific reaction depending upon previous sensitization. The altered tissue reaction in a broad biological sense as originally conceived by von Pirquet in 1906 when he coined the term allergy, now has included in the definition so many clinical conditions that it is impossible to use the term allergy without specifying what type of allergic reaction is involved. Broadly, we can consider the 'immediate' and the 'delayed' types of reaction, but the allergist when considering asthma is largely, although not exclusively, considering the allergic response of the immediate wheal and erythema found in association with smooth muscle contraction. The physiologists, pharmacologists and immunologists are dealing with a more definable scientific reaction when they describe an allergic response. This is not so when the clinician talks about the symptom ' asthma.' Asthma literally means ' gasping for breath.' There are many conditions which can cause a gasping for breath which are in no way related to disease of the bronchi or bronchioles. The dictum of Chevalier Jackson that all that wheezes is not asthma is true, and the quotation changed to all that wheezes is not allergy is also true. A simple definition of asthma is that it is a type of disease in which there are spontaneously recurring attacks of wheezing and dyspnoea. This is caused by functional bronchial and especially bronchiolar obstruction caused by varying degrees of oedema, spasm and secretions. There are often other naturally occurring allergic manifestations such as hay fever and atopic dermatitis, and there is a tendency towards a hereditary predisposition though the genetic inheritance of allergic diseases has never been proved.

Unger (1945), in his book on asthma, states that it is "a common condition . . . caused by hypersensitivity (allergy) to various excitants.' This seems an over-simplification of a symptom complex in which infections and emotions play such an important role in eliciting and aggravating the asthmatic symptoms. The patient with asthma has been aptly compared (Rackemann, I93I) to a loaded gun. We do not know why the gun is loaded, nor do we always know the trigger that fired the gun.

In an uncomplicated case of allergic asthma. the patient does not develop permanent emphysema. Patients have been seen who have had allergic asthma, yet they are able when free to represent their country in strenuous sport at international level. On the other hand, as the histo-pathological studies of Reid (1958) have shown, once infection develops in the wheezy bronchitic, then lung destruction begins. Chronic respiratory discomfort starts to appear, any exertion becomes exhausting, and after a few or many years pneumonia, cor pulmonate or an acute status asthmaticus attack ends the patient's life.

The terms asthma, bronchitis, asthmatic bronchitis and emphysema may in many countries refer to variations of the same complaint. This may explain to some extent why the English disease 'bronchitis' is so common here, while in America it is (allergic) asthma that is so common.

In a recent study at this hospital (Glynn and Michaels) a bronchial biopsy was taken from patients who had been admitted with asthma or bronchitis. The pathologist, who was not given the clinical diagnosis before he examined the sections, found that there was in most cases where the clinicians had diagnosed 'asthma' an eosinophilic infiltration of the subepethelial layer. Although in nearly all cases there was no obvious allergen to account for the asthma, the eosinophilia was suggestive of a possible basic allergic cause. Furthermore, the cells in asthmatic sputum are often (when not infected) largely eosinophilic, and the sharp-edged Charcot-Leydon crystals are believed to form from disintegrated eosinophil cells. It does not follow that, if in a bronchial biopsy or a stained specimen of sputum there is an increase of eosinophils, there will be blood eosinophilia. The eosinophil count normally declines during the morning and reaches a maximum between midnight and 3 o'clock. In the asthmatic patient this rhythm is reversed, and 


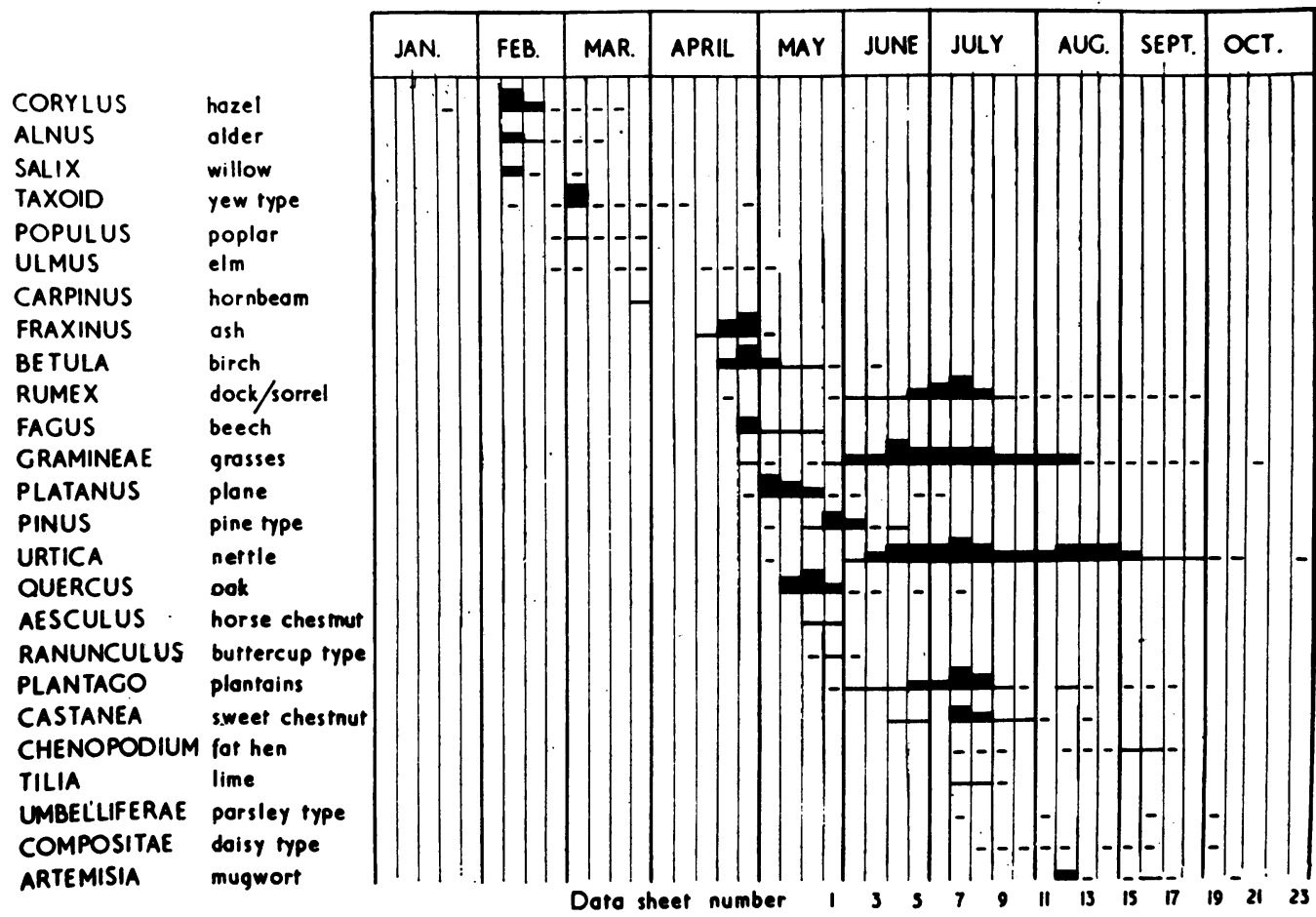

FiG. I-Chart showing seasonal incidence of various pollens.

the maximal count is between 9 and II o'clock in the morning (Arnoldsson and Helander, 1958).

Steroids in adequate dosage will greatly diminish blood eosinophils, but these cells are still found during steroid therapy in the bronchial biopsy and in the sputum. The Thorn test and its modifications which compare the eosinophil count before and after an injection of ACTH is of value in assessing adrenal function, and does not help to diagnose allergy. Eosinophils in the blood and in the sputum is an indication of allergy, and is the chief characteristic of the allergic reaction in man (Gay, 1946). The role of the eosinophil cell remains a mystery, but it seems in some way to represent the hosts' reaction to foreign protein (Briggs and Kerstraete, 1959), yet a clinical curiosity whose function and fate remain unknown.

\section{Bacterial Vaccines and Allergy}

No account of the place of allergy in asthma would be complete without mentioning the favour with which bacterial vaccines have been received as specific treatment for asthma of the infective type. Because respiratory infections often activate $\frac{\rho}{3}$ asthma, the idea has arisen that such patients might be sensitized by their own infecting organisms. Immediate and delayed type skin tests can be obtained when bacterial vaccines or filtrates are used. The majority of the immediate type skin reactions are due to the polysaccharide components, while the delayed type reaction is due to the protein faction (Swineford and Holman, 1949). The importance of the positive vaccine 9 skin test is not easy to evaluate clinically. Some investigators seem to believe that the benefit occurring from vaccine therapy is produced by $N$ increasing an immunity to the invading organisms; others have thought that vaccine administration has a desensitizing effect, and for this reason advised that vaccine therapy should be reserved $\underset{2}{2}$ for those showing a positive skin test to the 0 vaccine; some say only autogenous vaccines must be used, some find stock vaccines equally useful. While many authors have favoured pneumococcal and particularly streptococcal vaccine, Bergquist (1955) favours a staphylococcal vaccine. More recently influenza virus vaccine and trivalent 


\section{$1958 \quad$ FUNGUS SPORES}

\section{LONDON}

Wright-Fleming Instifute

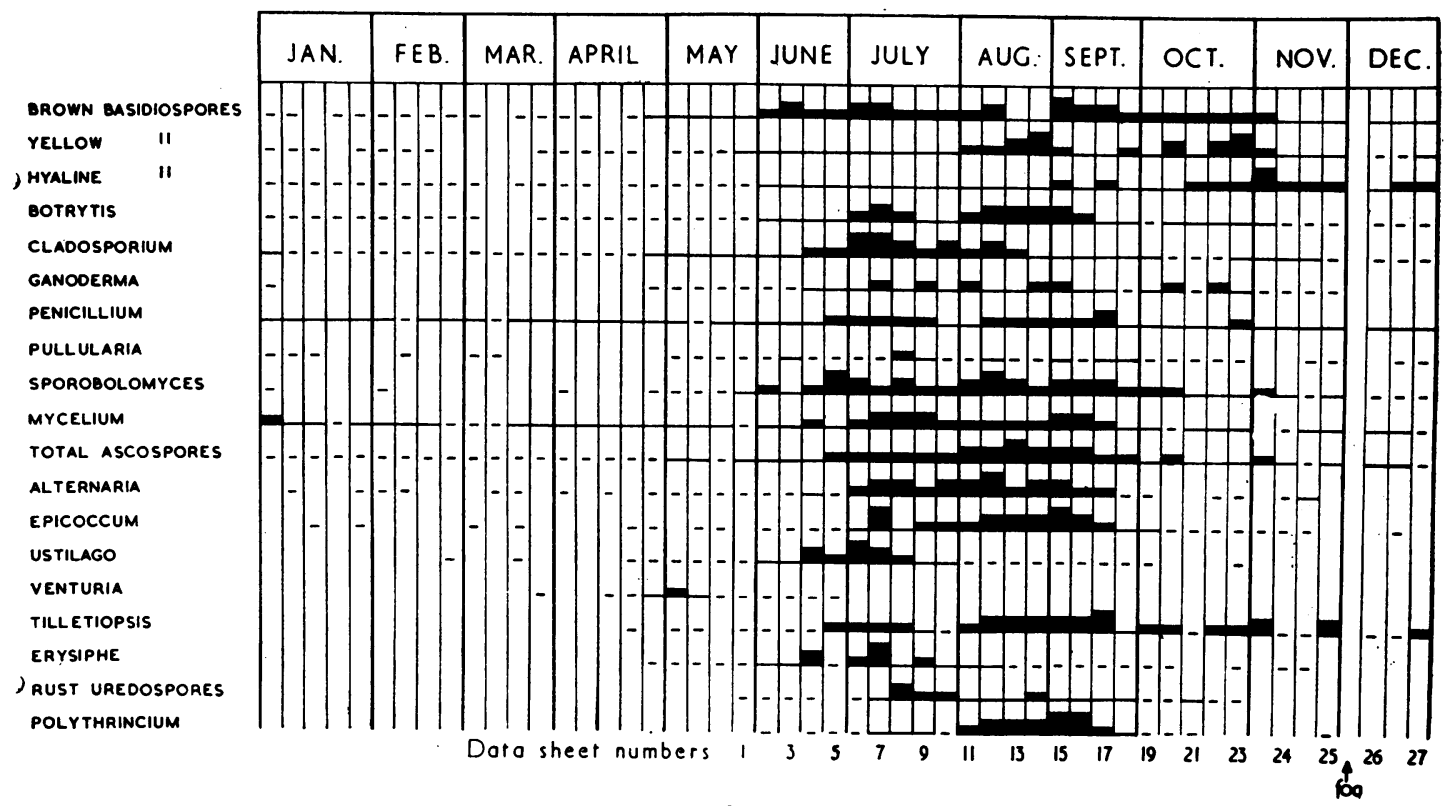

FIG. 2-Chart showing seasonal variations of some of the common types of fungal spores.
(APC) adenovirus vaccines have been used. Various investigators have used all sorts of widely differing vaccines, dosages and intervals between injections, and improvement was over 70 per cent. Frankland et al. (1955) found that there was no difference between the therapeutic effect of bacterial vaccines and placebo injections. These conclusions are in agreement with a more recent controlled trial by Helanger (1959), who considers that as a bacterial vaccine is not without some danger, only in exceptional cases should this method be used in infected asthma. Although his article would seem to ring the death knell to the use of bacterial vaccines in asthma, we can be quite sure that they will continue to be used with benefit in many asthmatic patients for many years to come.

\section{Skin Tests in Allergic Asthma}

It is a very good rule in asthma that skin tests should not be used to give information that has not already been found out from the history. This does not mean that skin tests will give no information, but that any positive responses are only clinically important if they conform with the clinical history. There is no point in carrying out a series of skin tests with various pollens unless it is known what time these are in the air.
A positive skin response to grass pollens, which are in the air largely in June and July, is not clinically important in someone whose symptoms occur in August and September. Many of the mould spores have definite seasonal peaks in much the same way as the pollens. Charts showing the times that pollens and moulds are in the air are therefore essential in eliciting the cause of seasonal asthma. Such charts (Figs. I and 2) must be used in conjunction with the results of skin tests. Daily pollen and mould spore counts throughout the year are carried out at the Wright-Fleming Institute, and these findings are invaluable to the allergist. For more detailed information about pollens and moulds, the reader is referred to Hyde and Williams (1959) and Hamilton (1959) and Maunsell (1954).

Seasonal symptoms in Great Britain, due to the moulds Cladosporium and Alternaria, are not uncommon for late summer asthma. The increasing importance of mould spore sensitivity as a cause of asthma is now being recognized. Unfortunately in the past mould spore extracts were often not strong enough to confirm a clinical mould spore sensitivity. A syndrome that seems to be becoming increasingly important, or perhaps now correctly diagnosed, is allergic pulmonary aspergillosis (Frankland and Hamilton, 1958). 
In this syndrome are found (i) asthma, (ii) high blood and sputum eosinophilia, and (iii) transient lung shadows on X-ray. These findings are caused by the inhalation of Aspergillus fumigatus into the lungs of a patient sensitive to the mould.

The purification and standardization of allergenic extracts is an ideal not yet attained. With the new immuno-chemical techniques now available (Augustin, r955) advances in the diagnosing and treatment of allergic asthma will be easier. The instability of dilute testing solutions in nearly empty bottles (Hjorth, 1958) is a factor which is of the greatest importance when considering the strength of any allergic extract, as the strength of a nearly empty bottle as measured by skin activity is only one-tenth that of the same bottle when full.

The method to be used in carrying out skin tests is that recommended by the manufacturers for the particular extract. Intracutaneous skin testing with a pollen solution should not be carried out. Patients who are very sensitive will give a positive response to as little as one Noon unit (one-millionth part of activity from I $\mathrm{g}$. of pollen) pricked through the skin. The prick test introduces 3-5 millionths of $\mathrm{I} \mathrm{ml}$. into the skin (Squire, 1950). Although skin testing is a simple procedure, and although it is an extremely sensitive method of showing the presence of reagenic antibodies in the skin, it must be remembered that quantitatively skin tests are grossly inaccurate (Augustin, 1959). Other methods of performing allergy tests are conjunctival testing as originally used by Noon (I9II). Provocation inhalation testing is also a useful method of testing for a specific sensitivity. It has been found (Citron, Frankland and Simpson, I958) that inhalation testing with a pollen aerosol in winter in pollen asthmatics could reproduce the symptoms of pollen asthma, but after desensitization a comparable test had no effect spirometrically. Although asthma was produced in a few minutes by the test and as quickly aborted by an inhalation of isoprenaline, quite a few patients redeveloped asthma in the middle of the night. The explanation of this finding is not known. It does indicate that asthma occurring at night may be related to the inhalation of an allergen by day which has not necessarily produced asthma at the time of inhalation.

\section{Incidence of Allergic Causes in Asthma}

In a study on 487 consecutive new asthmatic patients attending the asthma clinic at St. David's Hospital, Cardiff, an analysis was made of the dominant factor precipitating asthma (Williams et al., 1958). It was found that the allergic factor was important in 26 per cent., the infective factor in $4^{\mathrm{I}}$ per cent., and the psychological factor in 30 per cent. The infective factor was the sole factor causing asthma in I I per cent., $\stackrel{\mathbb{Q}}{\varrho}$ the psychological factor the sole cause in 1.1 per $C$ cent., and the allergic factor the sole cause in $\overrightarrow{\vec{F}}$ 3.3 per cent. Similar conclusions were reached by Pearson (1958). In a clinic specializing in allergic diseases the incidence of allergy in such a selected group is very much higher. Even so, in general it can be stressed that asthma is rarely $\Omega$ due to one cause only. Nevertheless, many patients with pollen asthma for many years will $\overrightarrow{0}$ have pollen as the only cause of their asthma. These patients without injection treatment do $\vec{\omega}$ not grow out of their asthma. Over the years the period of asthma may lengthen if a mould spore sensitivity develops. Finally, allergic causes seem less important as infective attacks give rise to chronic bronchitis and emphysema.

As a generalization, it can be stated that in the first decade of life the dominant causes of asthma of are infection and emotions, that in the second, third and fourth decades allergic causes predominate, and in the older age group infection is the predominating cause.

\section{Occupational and Industrial Asthma}

The pathogenesis of occupational asthma h危 $\overrightarrow{0}$ been largely dominated by physical and clinica points of view, and only recently has the allergi pathogenesis of occupational asthma been studied in some detail. Perhaps the best-known example of occupational asthma is bakers' asthma. Slowly the idea came that bakers' emphysema and bakers' bronchitis were better called bakers' asthma since $\overrightarrow{\vec{F}}$ rhinitis preceded the chest symptoms in many $\frac{0}{3}$ patients. Eventually many investigators in different countries began to look for specific allergic causes of the asthma. It was found that flour and $\bar{\partial}$ its impurities (dust, mites, moulds, etc.) were 3 responsible for allergic causes, though these were $\overline{0}$ frequently coupled with mechanically-acting causes. Bakers who have a hereditary tendency towards allergic diseases are more liable to get asthma than those who are not allergy prone. 을 It has been found (Gadborg, 1958) that there $D$ was a family history of allergy in 7.5 per cent. of bakers with no asthma, but 43 per cent. of those with asthma.

People therefore who are allergy prone are $\mathbb{O}$ more liable to get allergic asthma in the presence of a strong sensitizer than those who are not $\underset{\gamma}{ }$ allergy prone. (Frankland, 1953). It must be 0 remembered that bakers can have three months to 30 years' contact with flour before asthma develops. The time depends upon many factors which are qualitative (or genetic) for the patient, and qualitative and quantitative for the allergen.

The list of occupational allergic asthmas is very 
long, but has recently been reviewed (' Occupational Allergy,' r 958). A few occupations may be mentioned: bakers, millers, printers, castor-oil mill workers, poultry farmers, bird breeders, wood workers, zoologists, botanists, chemists, platinum smelters, doctors and nurses.

\section{Treatment of Allergic Asthma}

Asthma that has as its dominant causes allergic factors is much easier to treat than infective or psychological asthma. The basic treatment of allergic asthma is to find the cause, and if possible eliminate it. The history showing whether the asthma is seasonal or environmental, or both, will give the first clues that the asthma may be allergic. Eosinophils in blood and sputum and confirmatory skin tests are further aids in deciding upon the importance of allergic causes.

The patient himself will often know or suspect some of the causes of asthma, although the rhinitis that so often precedes asthma either as a chronic condition or as an acute exacerbation is often very difficult for the patient to distinguish from an infective cold. In children particularly there is often a low-grade temperature at the beginning of an attack of asthma, but this does not necessarily mean that the child has an infection which has given rise to the symptoms (Frankland, 1958).

When an attack is due to a cat, it should be easy to get rid of the cat. Prophylactic allergic advice is always worthwhile. When a child begins with eczema and later gets asthma it is likely that at first the common causes of the asthma are infective and emotional, while allergic factors in the very young generally are not very important triggers. If, however, birds and animals are in the house, and a hair mattress and feather pillows are used, it is likely that inhalant sensitivities will develop to these strong sensitisors.

It is, unfortunately, impossible to get away from some allergens, particularly pollens and moulds. Damp houses are notoriously unsuitable for asthmatics (Frankland and Hay, 195I) and fungal spores in general can be the source of indoor inhalant allergens (Maunsell, 1954).

\section{Symptomatic Treatment}

The treatment of allergic asthma is in general similar to the treatment of other types of asthma. The sympathomimetic drugs, adrenaline and ephedrine, still form the basic treatment of asthma. The xanthine derivatives theophyllineethylene-diamine is particularly efficacious given intravenously. It can also be given orally, intramuscularly and rectally.

One would expect that histamine is important in allergic asthma, and that the antihistamine drugs should be of benefit. In fact, antihistamines are not usually helpful in allergic asthma (Frankland and Gorrill, 1953). Antihistamines may, however, have some useful functions in asthma. Adrenaline in some patients produces no benefit, and the patient is said to be adrenaline-fast (or adrenaline refractory). This is believed to be due to the liberation of histamine (Farrerons-Co, 1949). An injection of an antihistamine before the adrenaline may be helpful in these patients.

One would hope that the atropine-like effect of the antihistamines would be of benefit to asthma, but atropine as opposed to stramonium seems to diminish the bronchial secretion excessively. There is no doubt that the sedative effects of the antihistamines is helpful, and this seems particularly noticeable in children.

Treatment by steroids is more fully described by Pearson (1959). Perhaps it should be stressed that allergic asthma generally reacts very well to steroid treatment. Failures of treatment can generally be attributed to inadequate dosage so that normally high dosage is required the first one or two days, and then the dose is slowly reduced. In allergic asthma, however, in which the patient is not in acute status, it is worth while trying low dosage for two days, e.g. prednisone $5 \mathrm{mg}$. three times a day, and observe whether this is sufficient to relieve completely the asthmatic symptoms.

The normal way to give steroids is by mouth (Rose and McGarry, 1959). Most workers (Smith, 1958) have failed to get the benefit reported by Herxheimer and McCallum (1956) by inhalation of hydrocortisone powder as snuff.

It is useful to remember that provided asthmatic sputum contains large numbers of eosinophils that steroids are very useful (Brown, 1958).

\section{Specific Injection Treatment}

Injection treatment has recently been reviewed by Bruun (1959). Dose schemes suitable for the patient are made up of the appropriate allergenic extracts. It must be remembered that a wrong dose or a dose given intravenously can kill the patient. Rush hyposensitizations (Freeman, 1930) in which the patient has four to six injections a day must be carried out in hospital.

Hansel (r953) for many years has recommended ' small dosage therapy.' Most allergists find that a few injections and a low dosage scheme do not give good results and certainly in pollen asthma (Frankland, 1955) high dosage of pollen extract gives better results than a low dosage scheme.

A more recent development has been the repository method of treatment (Loveless, 1957; Brown, 1959). A very high dosage of the allergenic extract is emulsified and given as a single 


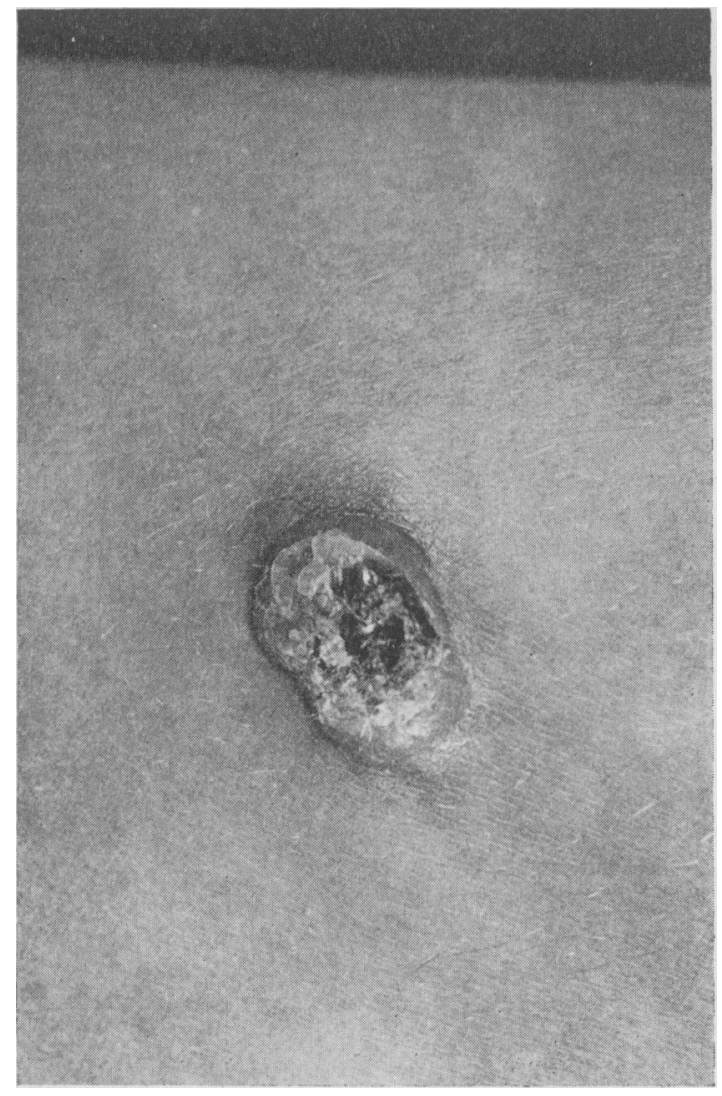

FIG. 3-Granulomatous ulcer after repository injection.

annual injection. In the few patients treated by the author, poor results have been obtained from the therapy. General reactions after the injection and tissue necrosis and ulceration lasting six months (Fig. 3) has caused abandonment of this method.
ARNOLDSSON, H., and HELANDER, E. (1958), Acta allerg (Kbh.), 12, 96.

AUGUSTIN, R. (1955), Quart. Rev. Allergy, 9, 504. .

AUGUSTIN, R. (1959), Immunology, 2, I.

BERGQUIST, G. (1955), Acta allerg. (Kbh.), 9, 97.

BRIGGS, D. K., and KERSTRAETE, M. (1959), in Jamar, J. M. Ed. 'Allergy,' Blackwell, Oxford.

BROWN, H. M. (1958), Lancet, ii, 1245.

BROWN, E. A. (1959), Ann. Allergy, 17, 34.
BRUUN, E. (1959), in Jamar, J. M., Ed. 'Allergy,' Blackwell $\overline{\frac{\Phi}{D}}$ Oxford.

CITRON, K., FRANKLAND, A. W., and SIMPSON, J. (1958) Thorax, 13, 229.

FARRERONS-CO, J. (1949), Ann. Allergy, 7, 46.

FRANKLAND, A. W. (1953), Ibid., II, 445.

FRANKLAND, A. W. (1955), Acta allerg. (Kbh.), 9, 183.

FRANKLAND, A. W. (1958), in Tizard, J. P. M., and Holzel, A. $\vec{\omega}$ Eds. 'Modern Trends in Paediatrics,' Butterworth, London. O

FRANKLAND, A. W., and HAY, M. (1951), Acta allerg. (Kbh. R

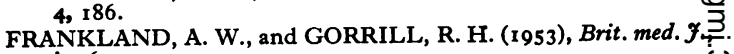
i, $76 \mathrm{r}$.

FRANKLAND, A. W., and HAMILTON, E. D. (1958), Allergier und Asthma, 4, 202.

FRANKLAND, A. W., HUGHES, W. H., and GORRILL, R. HO요 (1955), Brit. med.. ., ii, $94 \mathrm{r}$.

FREEMAN, J. (1930), Lancet, i, 740.

GADBORG, quoted by Bonnerie, P. (1958), ' Occupational Allergy, Kroese N.V., Leiden.

GAY L. N. (1946), "The Diagnoses and Treatment of Bronchial Asthma,' Williams and Watkins, Baltimore.

GLYNN, A. A., and MICHAELS, L. Personal communication.

HAMILTON, E. D. (1959), Acta allerg. (Kbh.), 13, 143.

HANSEL, F. K. (1953), ' Clinical Allergy,' p. 746, Mosby, St. Louis

HELANGER, E. (1959), Acta allerg. (Kbh.), 13, 47.

HERXHEIMER, H., and McALLEN, M. (1956), Lancet, i, $538 \overrightarrow{0}$ HJORTH, N. (1958), Acta. allerg. (Kbh.), 12, 316.

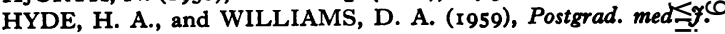
LOVELESS, M. (1957), F. Immunol., 79, 68.

MAUNSELL, K. (1954), Progr. Allergy, 4, 457.

NOON, L. (1911), Lancet, i, 1572.

'Occupational Allergy' (1958), Kroese N.V., Leiden.

PEARSON, R. S. Bruce (1958), Acta allerg. (Kbh.), 12, 227.

PEARSON, R. S. Bruce (1959), Postgrad. med. F.

PIRQUET, von C. (1906), Allergy, München med. Weknsehr., ${ }_{53}$, 1437.

RACKEMANN, F. M. (r931), 'Clinical Allergy, Asthma anc Hay Fever,' Macmillan, New York.

REID, L. (1058), in Oswald, N. C., 'Recent Trends in Chroniç Bronchitis,' Lloyd-Luke, London.

ROSE, B., and McGARRY, E. (1959), in Jamar, J. M., Ed:'Allergy,' Blackwell, Oxford.

SQUIRE, J. R. (1950), Clin. Sci., 9, 127.

SMITH, J. Morrison (1958), Lancet, ii, 1248.

SWINEFORD, O., and HOLMAN, J. (1949), $\mathcal{f}$. Allergy, 20, 1480

UNGER, L. (1945), 'Bronchial Asthma,' Thomas, Springfield.

WILLIAMS, D. A., et al. (1958), Acta allerg. (Kbh.), 12, 376.

\section{RUTHIN CASTLE, NORTH WALES}

A Clinic for the diagnosis and treatment of Internal Diseases (except Mental or Infectious Diseases). The Clinic is provided witn a staff of doctors, nurses, technicians, modern Radiological and Physiotherapy departments.

The surroundings are beautiful. The elimate is mild. There is central heating throughout. The annual rainfall is $\mathbf{3 0 . 5}$ inches, that is less than the average for England.

The Fees are inclusive and vary according to the room occupied.

For particulars apply to THE SECRETARY, Ruthin Castle, North Wales. 